Proceedings

\title{
Cardioprotective Effect of Juglone on Isoproterenol- Induced Myocardial Injury in SD Rats ${ }^{+}$
}

Taseer Ahmad 1,2, Taous Khan ${ }^{1}$, Abdul Jabbar Shah ${ }^{1,}$, Tahira Tabassum ${ }^{3}$, Sultan A. Almedhesh ${ }^{4}$, Hamdan Al shehri Al ${ }^{4}$, Alasmary Mohammed Yahia ${ }^{5}$, Mater H. Mahnashi ${ }^{6}$ and Mohammed N. Alqahtani 7

Published: 8 December 2020

1 Department of Pharmacy, COMSATS University Islamabad, Abbottabad Campus, University Road, Abbottabad KPK-22060, Pakistan; taseer.ahmad@uos.edu.pk (T.A.); taouskhan@cuiatd.edu.pk (T.K.)

2 Laboratory of Cardiovascular Research and Integrative Pharmacology, College of Pharmacy, University of Sargodha, Sargodha, , Punjab, 40100, Pakistan

3 Department Pathology, Sargodha medical college, University of Sargodha, Sargodha, Pakistan; tahira.tabassum@uos.edu.pk

4 College of Medicine, Najran University, Najran, 1988, Saudi Arabia; almedhesh31@hotmail.com (S.A.A.); hamdan-mohd1405@hotmail.com (H.A.s.A.)

5 College of Medicine, Internal Medicine Department, Najran University, Najran, 1988, Saudi Arabia; myalasmary@nu.edu.sa

6 Department of Medicinal Chemistry, Pharmacy School, Najran University, Najran, 1988, Saudi Arabia; matermaha@gmail.com

7 Ahad Rufaidah General Hospital, Abha-Ahad Rufaidah, 62219, Saudi Arabia; Xw212xw@gmail.com

* Correspondence: jabbarshah@cuiatd.edu.pk

+ Presented at the 1st International e-Conference on Antioxidants in Health and Disease, 01-15 December 2020; Available online: https://cahd2020.sciforum.net/.

Abstract: Therapeutic and/or preventive interventions using phytochemical constituents for ischemic heart disease have gained considerable attention worldwide, mainly due to its antioxidant activity. This study investigated the cardioprotective effect and possible mechanism of juglone, a major constituent of Walnut tree, using isoproterenol (ISO)-induced myocardial infarction (MI) model in rats. Rats were pretreated for five (5) days with juglone $(1,3 \mathrm{mg} / \mathrm{kg}$, i.p) and atenolol (1 $\mathrm{mg} / \mathrm{kg}$, i.p) in a separate experiments before inducing myocardial injury by administration of ISO $(80 \mathrm{mg} / \mathrm{kg}$, s.c) at an interval of $24 \mathrm{~h}$ for 2 consecutive days (4th and 5th day). The cardioprotective effect of juglone was confirmed through lead II electrocardiograph (ECG), the cardiac biomarkers (cTnI, CPK, CK-MB, LDH, ALT and AST) and histopathological study. The results of our present study suggest that prior administration of juglone proved to be effective as a cardioprotective therapeutic agent in reducing the extent of myocardial damage (induced by ISO) by fortifying the myocardial cell membrane, heart tissue architecture, preventing inflammation, edema, necrosis and also by normalizing cardiac marker enzymes (cTnI, CPK, CK-MB, LDH, ALT and AST). In conclusion, this study has identified phytochemical constituents: juglone as a potential cardioprotective agent.

Keywords: myocardial infarction (MI); juglone; antioxidant; isoproterenol; ECG; cardiac marker enzymes; histopathology 


\section{Introduction}

Myocardial ischemia or cardiac ischemia is characterized by an imbalance between myocardial oxygen supply and demand, causing cardiac dysfunction, arrhythmias, MI, and sudden death [1]. MI is defined as myocardial cell death due to prolonged ischemia [2]. There are approximately 32.4 million MI and strokes cases are reported globally every year [3]. The overall prevalence of IHD in Pakistan is $26.9 \%$ [4]. More than $30 \%$ of the population over 45 years of age is affected by MI [5]. MI is invariably followed by numerous pathophysiological and biochemical alterations like hyperlipidemia, thrombosis, lipid peroxidation (LPO), free radical damage and decline in nitric oxide (NO) level lead to qualitative and quantitative changes of myocardium [6]. The heart is one of the major organ affected by reactive oxygen species (ROS) and oxidative stress [7]. It has also been suggested that oxidative stress produced by free radicals or ROS, as evidenced by a marked increase in production of lipid peroxidative products associated with decreased levels of antioxidants defense system such as superoxide dismutase (SOD), catalase (CAT) and reduced glutathione peroxidase (GPx), plays a major role in myocardial damage during MI [8]. MI is also linked with the pathological alterations due to atherosclerosis. Atherosclerosis is by far the most common cause of MI [9]. In addition, pathophysiological alterations also include inhibition of NOS activity [10], over expression of calcium channels [11], cytosolic $\mathrm{Ca}^{2+}$ overload [12], blockade of potassium channels [10] and elevated cardiac markers: cardiac troponin I (cTnI), creatine phosphokinase (CPK), creatine kinasemyocardial band (CK-MB), lactate dehydrogenase (LDH), Alanine aminotransferase (ALT) and aspartate aminotransferase (AST) [13-15]. A gold standard marker for the diagnosis of MI is cardiac troponins (cTn) [16].

Cardioprotection includes all mechanisms and means that contribute to the preservation of the heart by decreasing or even preventing myocardial damage [17]. The principal pharmacological agents used in the treatment of MI are nitrovasodilators (nitroglycerine), $\beta$ adrenergic receptor antagonists (atenolol) and $\mathrm{Ca}^{2+}$ channel antagonists (verapamil). However, some limitations exist, such as, nitroglycerin and nitrates can cause vasodilation-induced headache, adverse effects of betablockers include, bradycardia, bronchoconstriction, sexual dysfunction and hypoglycemia and calcium channel blockers are potent vasodilators which lead to excessive hypotension, and reflex tachycardia [18]. In order to search for new cardioprotective agents the extracts and phytochemical constituents of many medicinal plants have been investigated and reported to possess cardioprotective effects mediated through different mechanisms $[19,20]$. Natural products including phenolic compounds have been the basis of treatment of ischemic heart diseases [21,22].

Juglone (5-hydroxy-1,4-naphthoquinone; Figure 1) is a phenolic compound from the black walnut tree (Juglans nigra) that has a wide range of properties considered beneficial to health. Juglans regia $\mathrm{L}$ extract is reported for antioxidant and cardioprotective effect against isoproterenol-induced myocardial infarction in rats [23,24]. In 1850s the juglone was first isolated from the walnut tree [25] and in 1881 the first scientific report on juglone allelopathic effect was published [26]. Juglone has been reported as allelopathic [26], vasorelaxant [27-30], antifungal [31,32], antitumour [33-35], antibacterial $[32,36]$ and antioxidant activity $[23,28,37,38]$. However, no study was found on the cardioprotective activity of juglone. Hence, the aim of our study was to examine the effects of juglone against isoproterenol-induced $\mathrm{MI}$ in rats.<smiles>O=C1C=CC(=O)c2c(O)cccc21</smiles>

Juglone 
The 1st International Electronic Conference on Antioxidants in Health and Disease, 1-15 December 2020

Figure 1. Chemical structure of juglone.

\section{Methods and Materials}

\subsection{Chemicals and Reagents}

Standard drugs like, atenolol and isoproterenol were purchased from Sigma-Aldrich, St. Louis, MO, USA. Pentothal sodium and heparin injections were obtained from Abbot Laboratories, Karachi, Pakistan and F. Hoffmann-La Roche, Basel, Switzerland, respectively. All drugs were dissolved in distilled water/normal saline except juglone. The juglone was 1st dissolved in dimethyl sulfoxide (DMSO) and then diluted with distilled water (the final in vivo study doses contain maximum $1 \%$ DMSO).

\subsection{Experimental Animals and Housing Conditions}

The cardioprotective activity was conducted on 8-10 week-old Sprague-Dawley (SD) rats (200$250 \mathrm{~g}$ ) (preferably male) were housed at the Animal House of the COMSATS University Islamabad, Abbottabad Campus, maintained at $23-25{ }^{\circ} \mathrm{C}$. Experiments performed complies with the rulings of the Institute of Laboratory Animal Resources, Commission on Life Sciences, National Research Council [39] (NRC, 1996) and approved by the Ethical Committee of Department of Pharmacy, COMSATS University Islamabad, Abbottabad campus, in its meeting held on 17-06-2013 video notification EC/PHM/07-2013/CIIT/ATD.

\subsection{Cardioprotective Study}

\subsubsection{Cardioprotective Study of Juglone against the Isoproterenol-Induced MI in Rats}

According to literature [40-42] with a slight modification the experimental myocardial infarction (MI) in rats was induced by administering isoproterenol (ISO) dissolved in normal saline and were administered at the dose of $80 \mathrm{mg} / \mathrm{kg}$ body weight subcutaneously (s.c) at an interval of $24 \mathrm{~h}$ for 2 consecutive days. The test compound, juglone at the doses of 1 and $3 \mathrm{mg} \mathrm{kg} /$ day were screened to determine the dose dependent effect of test compounds in ISO-induced myocardial infarction in rats.

The experimental animals were randomly divided into five groups consisting six rats in each group as shown in Table 1. Group I (Control group) rats received 1\% DMSO (1 mL kg/day, i.p.) for 5 consecutive days and normal saline $(1 \mathrm{~mL} / \mathrm{kg} /$ day, s.c.) on 4 th and 5 th day, at an interval of $24 \mathrm{~h}$. Group II (ISO group) rats received 1\% DMSO (1 mL/kg/ day, i.p.) for 5 consecutive days and ISO (80 $\mathrm{mg} \mathrm{kg}^{-1}$, s.c.) on $4^{\text {th }}$ and $5^{\text {th }}$ day, at an interval of $24 \mathrm{~h}$. Group III (atenolol + ISO) rats received atenolol ( $1 \mathrm{mg} / \mathrm{kg}$ i.p) for 5 consecutive days and then ISO $\left(80 \mathrm{mg} / \mathrm{kg}\right.$, s.c.) on $4^{\text {th }}$ and $5^{\text {th }}$ day, at an interval of $24 \mathrm{~h}$. Moreover, in Group IV \& V (juglone + ISO) juglone in two different doses (1 and $3 \mathrm{mg} / \mathrm{kg}$ i.p ) were administered via i.p route for 5 consecutive days and then ISO $\left(80 \mathrm{mg} / \mathrm{kg}\right.$, s.c.) on $4^{\text {th }}$ and $5^{\text {th }}$ day, at an interval of $24 \mathrm{~h}$. After $24 \mathrm{~h}$ of $2^{\text {nd }}$ dose of ISO $(80 \mathrm{mg} / \mathrm{kg}$, s.c. $)$, rats were anesthetized with sodium thiopental (Pentothal, $40-100 \mathrm{mg} / \mathrm{kg}$ body weight).

The body weight of all experimental rats was noted. Anesthetized rat was placed in a supine position. After complete induction of anesthesia, needle electrodes were inserted subcutaneously according to the lead II (left foreleg, right foreleg, and left rear leg) ECG scheme. ECGs were recorded using a PowerLab supplemented with an Animal BioAmp, analyzed by the LabChart 7 software (AD Instruments, Australia). After completion of ECG analysis, the rats were dissected and blood samples were collected through cardiac puncture. Hearts were removed, weighed, infarct area were estimated and preserved in formalin solution $(10 \%)$ for histopathology. The heart to body weight ratio of each animal was calculated to assess the degree of congestion [13]. 
The 1st International Electronic Conference on Antioxidants in Health and Disease, 1-15 December 2020

Table 1. This table shows the whole scheme of isoproterenol-induced myocardial Ischemia.

\begin{tabular}{|c|c|c|}
\hline S. NO. & Groups & Experiment Procedure \\
\hline 1 & Group I (Control group) & $\begin{array}{l}\text { - } \quad 1 \% \text { DMSO }(1 \mathrm{~mL} / \mathrm{kg} \text {, i.p.) for } 5 \text { consecutive days } \\
\text { - } \quad \text { Normal saline }(1 \mathrm{~mL} / \mathrm{kg} \text {, s.c. }) \text { on } 4 \text { th and } 5 \text { th day }\end{array}$ \\
\hline 2 & Group II (ISO group) & $\begin{array}{l}\text { - } \quad 1 \% \text { DMSO }(1 \mathrm{~mL} / \mathrm{kg} \text {, i.p.) for } 5 \text { consecutive days } \\
\text { - } \quad \text { ISO }(80 \mathrm{mg} / \mathrm{kg} \text {, s.c.) on } 4 \text { th and } 5 \text { th day, at an } \\
\text { interval of } 24 \mathrm{~h} \text {. }\end{array}$ \\
\hline 3 & Group III (Atenolol + ISO) & $\begin{array}{l}\text { - Group III received atenolol ( } 1 \mathrm{mg} \mathrm{kg}^{-1} \text { i.p) for } 5 \\
\text { consecutive days } \\
\text { - ISO }(80 \mathrm{mg} / \mathrm{kg} \text {, s.c.) on } 4 \text { th and } 5 \text { th day, at an } \\
\text { interval of } 24 \mathrm{~h} \text {. }\end{array}$ \\
\hline 4 & $\begin{array}{c}\text { Group IV ,V (Juglone + } \\
\text { ISO) }\end{array}$ & $\begin{array}{l}\text { - Juglone in two different doses ( } 1 \text { and } 3 \mathrm{mg} / \mathrm{kg} \text { i.p) } \\
\text { for } 5 \text { consecutive days. } \\
\text { - ISO }(80 \mathrm{mg} / \mathrm{kg} \text {, s.c.) on } 4 \text { th and } 5 \text { th day, at an } \\
\text { interval of } 24 \mathrm{~h} \text {. }\end{array}$ \\
\hline
\end{tabular}

\subsubsection{Biochemical Estimations in Serum}

The serum were separated by centrifugation for biochemical analyses. The cardiac marker enzymes, such as aspartate transaminase (AST), alanine transaminase (ALT), creatine phosphokinase $(\mathrm{CPK})$, creatine kinase-MB (CK-MB), lactate dehydrogenase (LDH) and cardiac troponin I were estimated using commercially available standard assay kits (Standbio Laboratory, Boerne, TX, USA; JAJ International Inc., San Diego, California, USA). The serum markers were estimated in the serum according to procedure followed Kim et al. 2015 [13] and Ighodaro et al., 2018 [15].

\subsubsection{Histopathological Examination}

After sacrifice, the heart tissues were rapidly dissected out and washed immediately with icecold normal saline and fixed in $10 \%$ buffered formalin. Then rats heart samples were dehydrated in graded $(80-100 \%)$ alcohol and cleared in xylene. The fixed tissues were embedded in paraffin, $5 \mathrm{~mm}$ sections were prepared with the help of microtome and stained with hematoxylin $(\mathrm{H})$ and eosin $(\mathrm{E})$ stains for light microscopy. The $\mathrm{H}$ and $\mathrm{E}$ stains were used to impart colors to a specimen. The stained sections under light microscope were examined for myocardial changes, such as changes in branches of cardiac muscles fibers, inflammation, edema and necrosis. These slides were photographed through advanced research microscope [40, 43].

\subsection{Statistical Analysis}

Statistical analysis of the biochemical data were determined by using one way ANOVA followed by tukey's test through GraphPad Prism Software, version 8 (Graph Pad, San Diego, CA, USA). A $p$ value of less than $0.05\left({ }^{*} p<0.05\right)$ was considered statistically significant. 


\section{Results}

\subsection{Cardioprotective Effect of Juglone against the Isoproterenol (ISO)-Induced Myocardial Injury in Rats}

\subsubsection{Effect of Juglone on Electrocardiograph (ECG) Parameters}

Control group rats treated with 1\% DMSO alone did not show any change in electrocardiograph pattern (Figure 2A). While ISO-treated rats showed marked ST-segment elevation and deep Q wave (Figure 2B). These changes were restored to nearly normal with atenolol (1 mg/kg) (Figure 2A) and juglone (1 and $3 \mathrm{mg} / \mathrm{kg}$ ) (Figure 2B,C), pretreatment and co-treatment when compared with isoproterenol-alone treated rats.

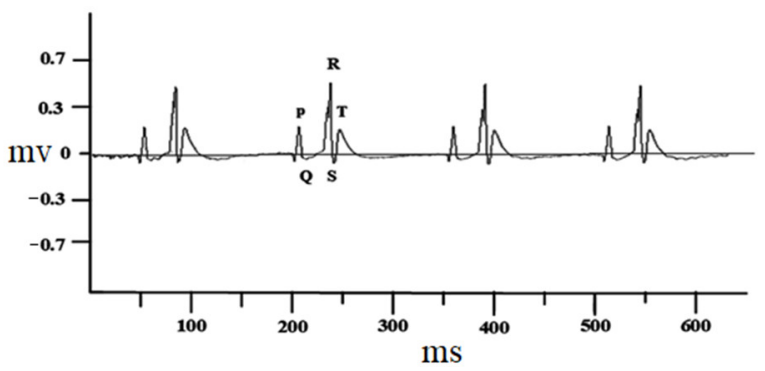

(A)

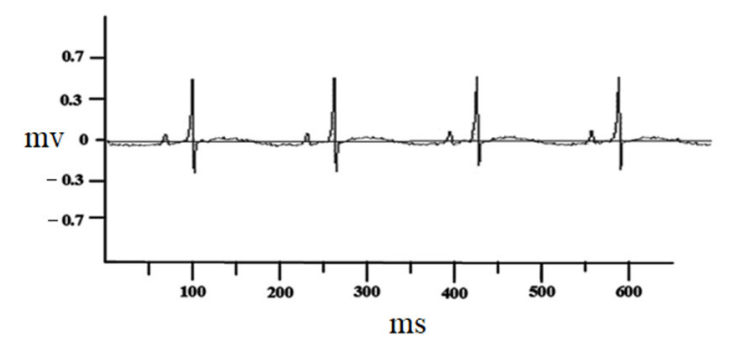

(C)

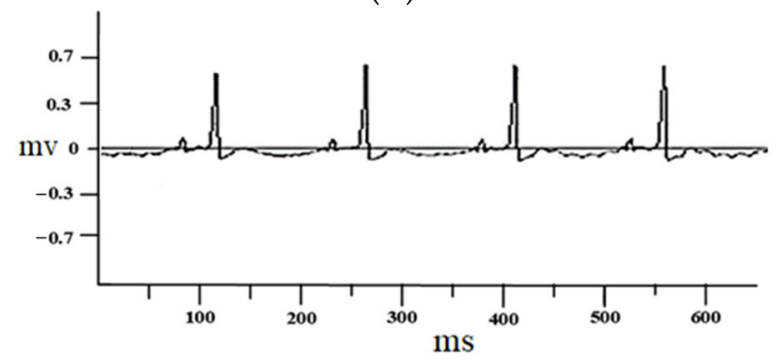

(E)

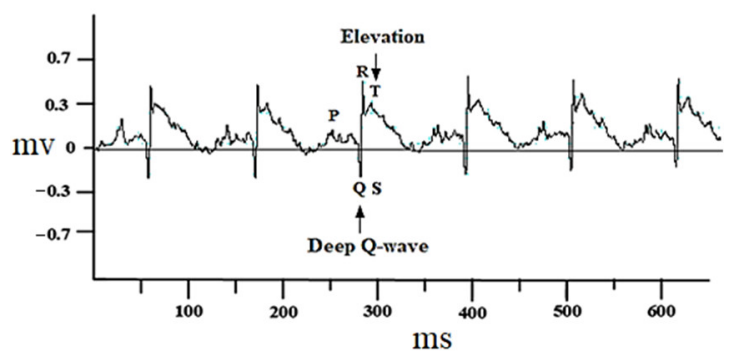

(B)

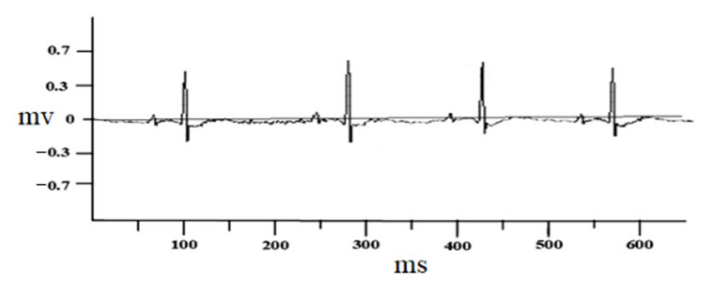

(D)

Figure 2. Representative electrocardiogram (ECG) tracing of control (A), isoproterenol (B), atenolol (1 $\mathrm{mg} / \mathrm{kg}$ ) + ISO (C), juglone $1 \mathrm{mg} / \mathrm{kg}+\mathrm{ISO}(\mathbf{D})$ and $3 \mathrm{mg} / \mathrm{kg}+\mathrm{ISO}(\mathbf{E})$ treated rats (recorded from lead II with recording speed $50 \mathrm{~ms} / \mathrm{div})$. millisecond (ms), millivolt (mv).

\subsubsection{Effect of Juglone on Heart and Body Weight Ratio}

The mean body weight of rats at the end of experiment period in all experimental groups had no significant changes observed (data not shown). The heart weight and the ratio of heart weight to body weight were increased significantly $(p<0.001)$ in ISO-administered groups when compared with normal control groups. Rats pre-co-treated with the atenolol and juglone ( $1 \mathrm{mg} \& 3 \mathrm{mg})$ showed a significant reduction in heart weight and ratio as compared to ISO-alone treated groups (Figure 3). 


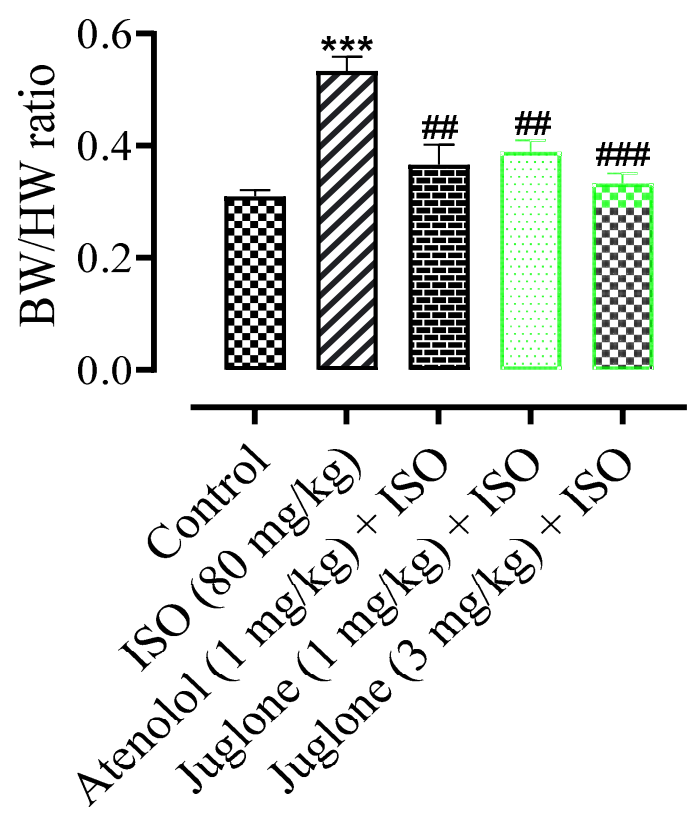

Figure 3. Effect of juglone + ISO, atenolol + ISO and ISO alone on body weight/heart weight (BW/HW) ratio in comparison to control. Values are expressed as Mean $\pm \operatorname{SEM}(n=6)$. Where ${ }^{\sharp} p<0.01$ vs. ISO, $\# \#<0.001$ and ${ }^{* * *} p<0.001$ vs. Control. (One-way ANOVA followed by a Tukey's test).

\subsubsection{Changes in the Rat Heart Structural Anatomy and Measurement of Myocardial Infarct Size}

In comparison to control group the rat heart shape was change from elliptical to spherical when treated with isoproterenol $(80 \mathrm{mg})$ and the heart shape is significantly protected in the atenolol (1 mg) and juglone $(1 \mathrm{mg} / \mathrm{kg} \& 3 \mathrm{mg} / \mathrm{kg}$ ) treated groups. The infarcted myocardium appeared pale grey or white, from which the percent infarct area was identified. The infarction was significantly prevented in the treated groups; atenolol (15\%) and diosmetin $1 \mathrm{mg}(15 \%)$ and $3 \mathrm{mg}(10 \%)$ as compared to isoproterenol (55\%), as shown in Figure 4.

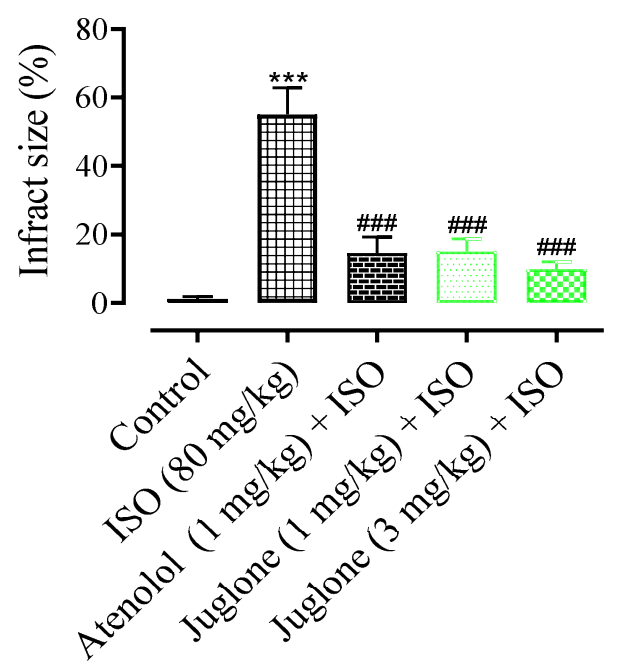

Figure 4. The graph shows the percent myocardial infarct size in the control and experimental animals. Values are expressed as mean $\pm \operatorname{SEM}(n=6)$. Where ${ }^{\# \#} p<0.001$ vs. ISO and ${ }^{* * *} p<0.001$ vs. Control (One-way ANOVA followed by a Tukey's test). 
As shown in Figure 5, there was a significant elevation observed in the serum levels of diagnostic marker enzymes (cTnI, CPK, CK-MB, LDH, ALT and AST) in the serum of ISO-alone administered rats. Compared with the control, ISO-alone caused significant increase in the serum level of myocardial injury biomarkers, cTnI $(82.0 \pm 3.01 \%), \mathrm{CPK}(49.50 \pm 4.01 \%), \mathrm{CK}-\mathrm{MB}(54.04 \pm 2.01 \%), \mathrm{LDH}$ $(60.25 \% \pm 5.01 \%)$, ALT $(46.8 \pm 3.02 \%)$ and AST $(51.3 \pm 2.02 \%)$. Pretreatment with atenolol $(1 \mathrm{mg} / \mathrm{kg})$ significantly restored the serum level of the cardiac biomarkers alterations induced by ISO, such as cTnI $(48.52 \pm 1.02 \%)$, CPK $(24.75 \pm 1.24 \%)$, CK-MB $(53.0 \pm 1.54 \%)$, LDH $(27.30 \pm 4.02 \%)$, ALT $(24.13 \pm$ $2.02 \%)$, AST $(27.34 \pm 1.91 \%)$. Pretreatment of juglone $(1 \mathrm{mg} / \mathrm{kg})$ significantly decrease the serum level of cTnI ( $42.64 \pm 1.91 \%)$, CPK $(28.12 \pm 1.68 \%), \mathrm{CK}-\mathrm{MB}(54.36 \pm 2.11 \%), \mathrm{LDH}(54.36 \pm 5.02 \%)$, ALT $(18.14$ $\pm 1.14 \%)$, AST $(19.0 \pm 2.05 \%)$. In addition, pretreatment with juglone $(3 \mathrm{mg} / \mathrm{kg})$ also significantly restored the serum level of the cardiac biomarkers alterations induced by ISO, such as CTnI $(63.23 \pm$ $1.25 \%), \mathrm{CPK}(32.22 \pm 2.51 \%), \mathrm{CK}-\mathrm{MB}(58.35 \pm 3.01 \%), \mathrm{LDH}(58.85 \pm 6.01 \%), \mathrm{ALT}(59.01 \pm 3.10 \%)$ and AST $(48.01 \pm 3.31 \%)$ as compared to ISO-alone treated group (Figure 5A-F).

(A)

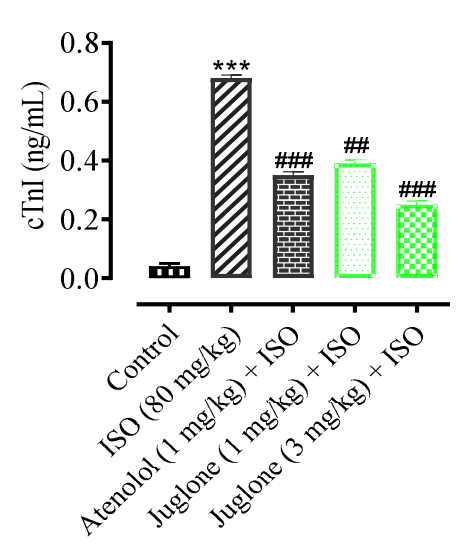

(C)

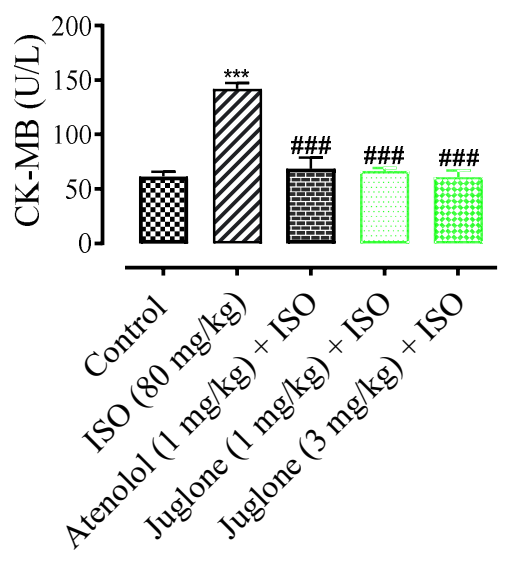

(B)

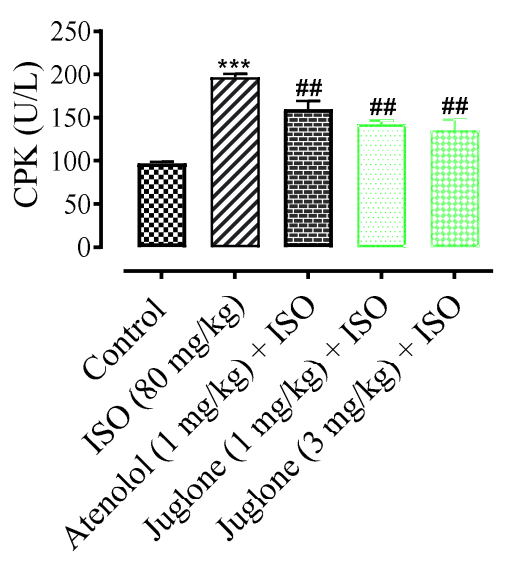

(D)

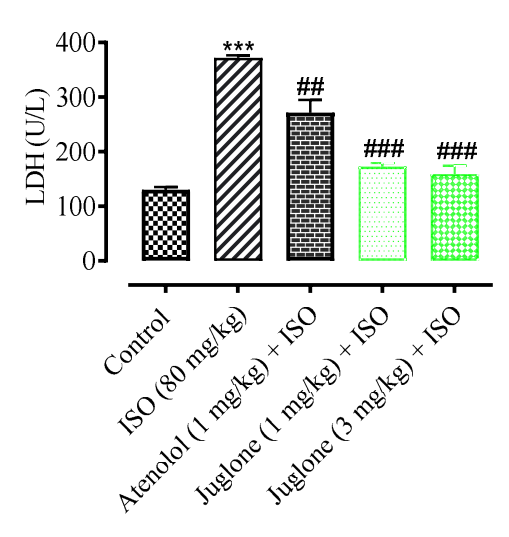


(E)

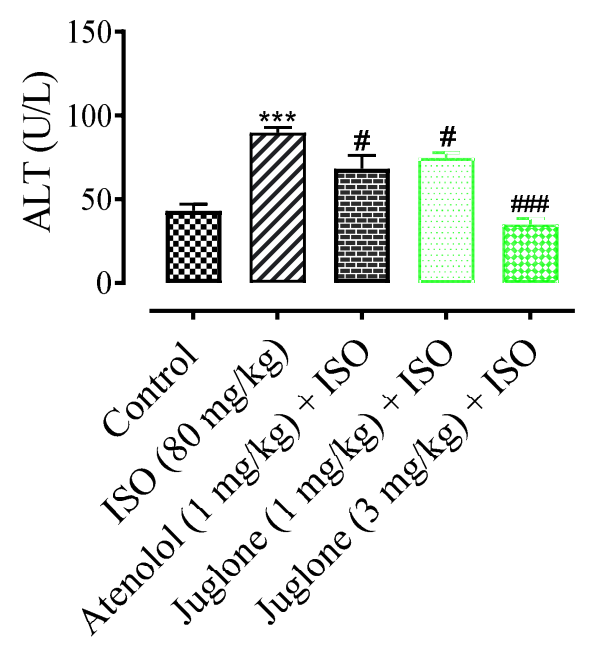

(F)

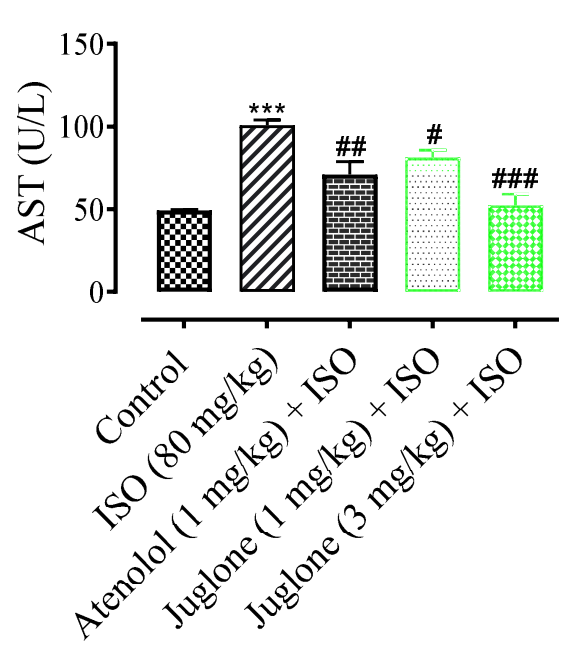

Figure 5. Effect of juglone and atenolol on cardiac troponin I (cTnI) (A) creatine phosphokinase (CPK) (B), creatine kinase-MB (CK-MB) (C), lactate dehydrogenase (LDH) (D), alanine transaminase (ALT) (E) and aspartate transaminase (AST) (F) in isoproterenol (ISO)-induced ischemic rats. Values are expressed as Mean \pm SEM ( $\mathrm{n}=6$ ). Where ${ }^{\#} p<0.01$ vs. ISO, \#\# $p<0.001$ vs. ISO and ${ }^{* * *} p<0.001$ vs. Control. (One-way ANOVA followed by a Tukey's test). Where ${ }^{\sharp} p<0.05$ vs. ISO, ${ }^{\#} p<0.01$ vs. ISO, \#\#\# $p<0.001$ vs. ISO and ${ }^{* * *} p<0.001$ vs. Control. (One-way ANOVA followed by a Tukey's test).

\subsubsection{Effect of Juglone on Histological Changes}

Histopathological observations of control rat heart showed a normal morphology of cardiac muscle fibers with striations and branched appearance (Figure 6A). ISO-induced rats revealed marked inflammation, edema and necrosis (Figure 6B). The tissue sections from all treated groups, atenolol $(1 \mathrm{mg} / \mathrm{kg})+$ ISO (Figure 6C) and juglone $(1 \& 3 \mathrm{mg} / \mathrm{kg})+$ ISO (Figure 6D,E) showed less inflammation and edema and also the morphology of cardiac muscle fibers was relatively well preserved with minimum evidence of necrosis when compared to ISO-induced group, as shown in Figure 6 and Table 2. 


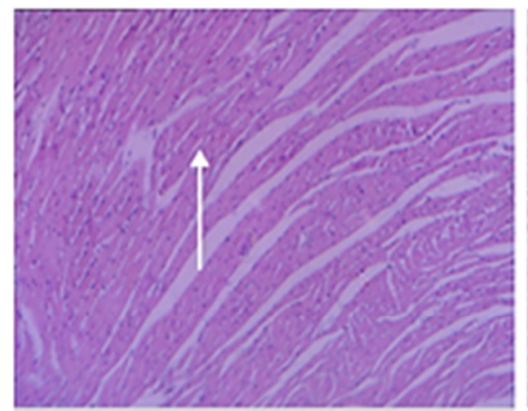

(A) Control

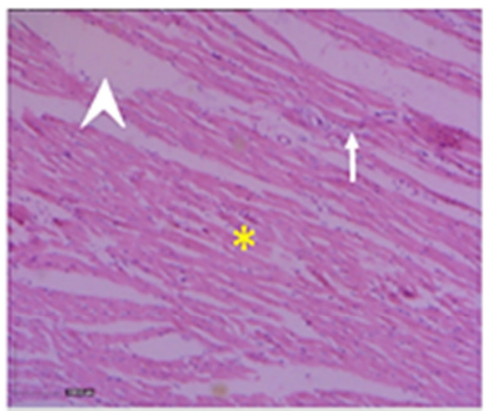

(B) $I S O(80 \mathrm{mg} / \mathrm{kg})$

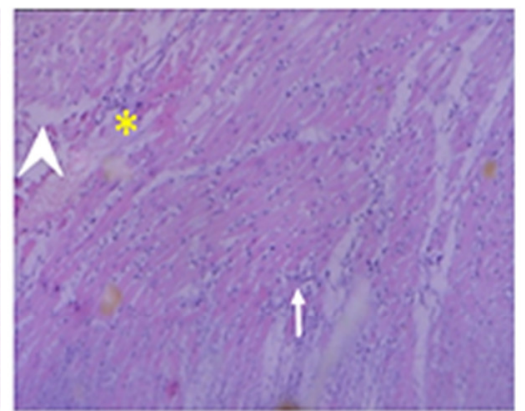

(C) Atenolol (1 mg/kg) +ISO

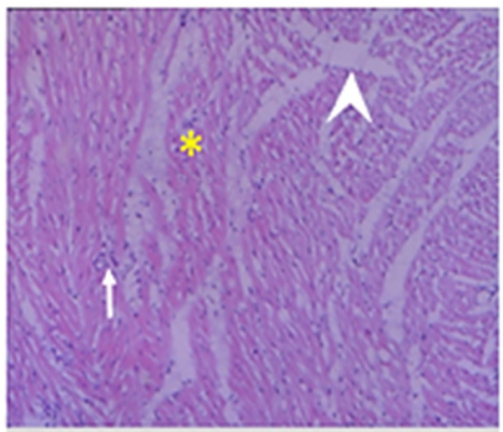

(D) Juglone (1 mg/kg) + ISO

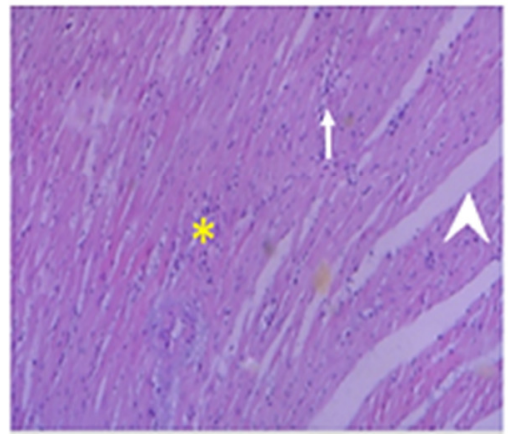

(E) Juglone (3 mg/kg) + ISO

Figure 6. Heart tissue (H\&E, 200×) of (A) control, shows normal cardiomyocytes (arrow), (B) isoproterenol (ISO)-alone treated shows marked inflammation (arrow), edema (arrow head) and confluent necrosis (esteric), (C) Pretreatment with atenolol + ISO produced moderate reduction in inflammation (arrow), edema (arrow head) and necrosis (esteric), (D) 1mg/kg juglone + ISO produced moderate reduction of inflammation (arrow), edema (arrow head) and necrosis (esteric) and (E) 3 $\mathrm{mg} / \mathrm{kg}$ juglone + ISO produced maximal reduction of inflammation (arrow), edema (arrow head), and necrosis (esteric), respectively.

Table 2. Preventive effects of juglone and atenolol on the degree of histological changes in myocardium of isoproterenol (ISO)-administered ischemic rats.

\begin{tabular}{cccc}
\hline Groups & Inflammation & Edema & Necrosis \\
\hline Control & - & - & - \\
ISO $(80 \mathrm{mg} / \mathrm{kg})$ & +++ & +++ & +++ \\
Atenolol $(1 \mathrm{mg} / \mathrm{kg})+\mathrm{ISO}$ & + & + & + \\
Juglone $(1 \mathrm{mg} / \mathrm{kg})+\mathrm{ISO}$ & + & ++ & + \\
Juglone $(3 \mathrm{mg} / \mathrm{kg})+\mathrm{ISO}$ & + & + & + \\
\hline
\end{tabular}

The signs indicate; -, absent; +, mild changes; ++ moderate changes; and +++, marked changes, ISO; Isoproterenol.

\section{Discussion}

To test juglone as possible cardioprotective, ISO-induced myocardial ischemic model in rats was developed. Furthermore, the plant source of juglone is reported for antioxidant and cardioprotective activities [24]. ISO is a synthetic catecholamine and non-selective beta-adrenergic receptor agonist. $\beta$ adrenergic receptor $(\beta-\mathrm{AR})$ signaling is the primary mechanism to increase cardiac contractility. However, chronic $\beta$-AR stimulation, which occurs in MI, results in dysregulation of the $\beta$-adrenergic pathway, leading to activation of protein kinase A (PKA)-dependent phosphorylation of L-type calcium channels which in response lead to increase in the intracellular calcium level and oxidative stress $[44,45]$. A subcutaneous injection of a high dose of isoproterenol caused a severe stress in the 
The 1st International Electronic Conference on Antioxidants in Health and Disease, 1-15 December 2020 myocardium resulting in necrosis of the heart muscles, elevated ST-segment and deep Q-wave in the ECG and structural changes in the heart very similar to that occurs in patients with MI [46]. Increased heart rate leads to increase oxygen consumption and accelerate myocardial necrosis [40]. Despite of some differences, there are essential similarities between rat and human ECG [47]. Rat myocardial changes induced by ISO are nearly similar to human myocardium changes during MI [48].

The ECG is considered one of most important initial clinical marker for diagnosing MI. Its correct interpretation is usually the basis for immediate therapeutic interventions and/or subsequent diagnostic tests. ECG abnormalities such as ST-segment elevation and deep Q-wave could be due to the successive loss of cell membrane and absence of electrical activity in the injured myocardium [49]. ST-elevation myocardial infarction (STEMI) is an event in which transmural myocardial ischemia results in myocardial injury or necrosis [50]. Pretreatment of ISO-treated rats with different doses of juglone and standard drug, atenolol markedly restrained ISO-induced changes in ECG pattern, STsegment elevation and deep Q-wave, suggesting membrane protecting effects. Juglone highly significantly restored the ECG pattern at maximum doses $(3 \mathrm{mg} / \mathrm{kg})$. The cardioprotective action of juglone was further confirmed.

Myocardium contains an abundant amount of diagnostic marker enzymes for MI and once metabolically damaged, these contents release into the extracellular fluid [51]. According to the 2018 clinical definition, MI confirmation requires the validation of the cardiac injury with abnormal cardiac biomarkers [52]. The ISO administration to the rats also caused the leakage of cardiac marker enzymes such as CTnI, CPK, CK-MB, LDH, AST and ALT, which may be due to myocardial necrosis, damage or destruction of cell membrane, deficiency of oxygen (hypoxia) or glucose. Moreover, increase in heart to body weight ratio with abnormal histo-architecture of heart tissue indicated ISOinduced myocardial damage, which was in line with the previous reports [53-56].

Pretreatment with juglone ( 1 and $3 \mathrm{mg} / \mathrm{kg}$, respectively) and standard drug, atenolol followed by ISO administration significantly $(p<0.001)$ decreased the difference in the heart to body weight ratio and infarct size when compared to ISO-alone treated rats. The infarct area observed in rats pretreated with juglone was also reduced significantly $(10 \%)$. Furthermore, juglone also significantly decreased (63\%) the serum levels of cTnI. Cardiac troponin is a gold standard for diagnosing a MI. The 3-subunits of troponin complex troponin C (TnC), troponin T (TnT) and troponin I (TnI) along with tropomyosin is located on the actin filament and is crucial for the calcium-mediated regulation of cardiac muscle contraction [57,58]. cTnI and cTnT specific to cardiac muscles, are the most common indicators for the diagnosis of heart damage after MI. cTnI is more sensitive to cardiac injury as compared to cTnT [59]. Troponin levels become elevated within 2 to 3 hrs after the onset of MI, reaches to peak at 18-24 hrs, and remain elevated for up to 14 days. The half-life of circulating troponin is nearly $2 \mathrm{hrs}$. So, it stays in bloodstream for days after all other biomarkers returned to normal levels [49].

The appearance of CPK in the blood has been generally considered to be an indirect marker of cardiac muscle damage. The significant decrease (32\%) in the serum level of CPK was observed with juglone. Juglone also produces the highly significant decrease (58\%) in the serum level of CK-MB. CPK is an enzyme that catalyzes the phosphorylation of creatine. By utilizing adenosine triphosphate, CPK converts creatine to phosphocreatine and adenosine diphosphate. CPK can be measured several times over a 24 hrs period [60,61]. CK is found in both the cytosol and mitochondria of tissues. The cytosolic CK is composed of two types of subunit: M (muscle type) and B (brain type). These subunits allow the formation of three tissue-specific isoenzymes: CK-MB (cardiac muscle), CK-MM (skeletal muscle) and CK-BB (brain). CK-MB is more sensitive to heart damage following MI. CK-MB is detectable in the blood within 3 to 5 hrs after a MI, rises to peak within 12-24 hrs, and back to normal within a day or two [62,63].

The high level of LDH concentrations in the blood is indicative of tissue damage and inflammatory changes, particularly in the heart [64]. Juglone significantly reduced (58\%) the serum level of LDH. LDH is an enzyme found in almost every cell mainly presents in myocardium, skeletal 
The 1st International Electronic Conference on Antioxidants in Health and Disease, 1-15 December 2020 muscle, liver and kidneys. In heart, LDH is present in both mitochondria and surrounding cytosol and organelles. The LDH turns sugar into energy [65]. LDH isoenzyme level increase 24-72 hours following MI and reach a peak concentration in 3-4 days. The levels remain elevated for 8 to 14 days. LDH is considered a non-specific marker for MI [16].

The concentrations of AST and ALT in the serum at normal physiological condition are low. However, the level of these markers increases following MI, causing leakage of AST, ALT into the blood circulation. The juglone highly significantly decrease (59\%, 48\%) the serum level of these enzymes. ALT is mainly located in the cytoplasm, while AST is present both in the cytoplasm and mitochondria, that's why AST is more sensitive to cardiac injury as compared to ALT. After MI, AST and ALT is elevated at 6 to 10 hrs, peaks at 24-36 hrs that remain high for 3-5 days. In addition to ALT and AST in diagnosing MI have been replaced by newer enzyme and protein that are more specific for cardiac damage like cTnI, CPK, CK-MB and LDH [66,67]. It demonstrated that juglone could maintain cardiac membrane structural and functional integrity and/or permeability, thereby restricting the leakage of the cardiac biomarkers from the myocardium. These effects are evident from the markedly blunted levels of cardiac biomarkers in juglone + ISO groups when compared to the ISO-alone treatment group, thereby establishing the cardioprotective effects of juglone.

Furthermore, the preliminary histopathological findings of the ISO-induced MI group myocardium showed large infarcted zone with, inflammation, edema, coagulative necrosis and separation of cardiac muscle fibers. In rats, ISO had been reported to increase oxygen demand, deplete ATP levels, cause calcium overload and undergo autoxidation leading to formation of free radicals [68]. However, juglone and atenolol pretreatment followed by ISO considerably prevented the pathological changes such as inflammation, edema and necrosis when compared to ISO-alone treated rats. Previous studies found that juglone showed a significant free radical scavenging activity $[38,69]$. The structure of juglone (Figure 1) contains hydroxyl groups in the benzene ring, which may explain its ability to scavenge free radicals [70]. Moreover, the plant source of juglone, Juglans regia extract improved the activities of superoxide dismutase (SOD) and catalase (CAT) by scavenging superoxide and hydrogen peroxides produced by ISO [24]. Administration of submaximal doses of ISO had been reported to induce severe oxidative stress [71,72]. The generation of ROS occurs by the leakage of electrons into oxygen from various systems. Overproduction of ROS can cause severe impairment of cellular functions and necrotic lesions in the myocardium of rats. In contrast, superoxide dismutase (SOD), catalase (CAT) and glutathione peroxidase (GPX) constitute a mutually supportive and free radical scavenging enzymes team of 1st line defense against oxidative injury [73]. The plant source of juglone, Juglans regia is also reported to inhibit increase in intracellular malondialdehyde (MDA) level [74]. MDA and its measurement has been used as indicator of lipid peroxidation [75]. Lipid peroxidation is considered a major mechanism of oxygen free radical toxicity [76]. Zhou et al. (2015) [77] demonstrated that juglone increased the activity of SOD and decreased oxidative stress. Moreover, juglone also activates mitogen-activated protein kinases (MAPK) that could promote cell survival, thereby protecting against conditions such as cardiac injury [35]. These reported activities of juglone suggest that it might be possible that their antioxidant effect have played as cardioprotective.

These primary findings of our study indicate the cardioprotective effect of juglone. The most significant effects was observed at higher doses ( $3 \mathrm{mg} / \mathrm{kg})$. In summary, these experimental evidence might be helpful to understand the beneficial effects of juglone against myocardial injury although further studies are needed to confirm its mechanisms.

\section{Conclusions}

In conclusion, the results of our present study also suggest that prior administration of juglone proved to be effective as a cardioprotective therapeutic agent in reducing the extent of myocardial damage (induced by ISO) by fortifying the myocardial cell membrane and heart tissue architecture and also by normalizing biochemical parameters like cardiac marker enzymes. Further electrophysiological studies would provide more insight into the molecular aspects of this study. 
Conflicts of Interest: The authors declare no conflict of interest.

\section{References}

1. Shimokawa, H.; Yasuda, S. Myocardial ischemia: Current concepts and future perspectives. J. Cardiol. 2008, 52, 67-78.

2. Jennings, R.B.; Reimer, K.A. Factors involved in salvaging ischemic myocardium: Effect of reperfusion of arterial blood. Circulation 1983, 68, 125-136.

3. World Health Organization (WHO). Cardiovascular Disease. Prevention of Recurrences of Myocardial Infarction and Stroke Study. 2019. Available online: https://www.who.int/ cardiovascular_diseases/ priorities /secondary_prevention/country/en/index1.html (accessed on 12 $2^{\text {th }}$ December, 2019).

4. Jafar, T.H.; Islam, M.; Poulter, N.; Hatcher, J.; Schmid, C.H.; Levey, A.S.; Chaturvedi, N. Children in South Asia Have Higher Body Mass-Adjusted Blood Pressure Levels Than White Children in the United States A Comparative Study. Circulation 2005, 111, 1291-1297.

5. Saleem, F.; Hassali, A.A.; Shafie, A.A. Hypertension in Pakistan: Time to take some serious action. Br. J. Gen. Pract. 2010, 60, 449-450.

6. Hegstad, A.C.; Ytrehus, K.; Myklebust, R.; Jørgensen, L. Ultrastructural changes in the myocardial myocytic mitochondria: Crucial step in the development of oxygen radical-induced damage in isolated rat hearts? Basic Res. Cardiol. 1994, 89, 128-138.

7. Misra, M.K.; Sarwat, M.; Bhakuni, P.; Tuteja, R.; Tuteja, N. Oxidative stress and ischemic myocardial syndromes. Med. Sci. Monit. 2009, 15, RA209-RA219.

8. Wu, J.; Hecker, J.G.; Chiamvimonvat, N. Antioxidant enzyme gene transfer for ischemic diseases. Adv. Drug Deliv. Rev. 2009, 61, 351-363.

9. Rezende, P.C.; Ribas, F.F.; Serrano, C.V.; Hueb, W. Clinical significance of chronic myocardial ischemia in coronary artery disease patients. J. Thorac. Dis. 2019, 11, 1005-1015.

10. Baker, J.E.; Su, J.; Fu, X.; Hsu, A.; Gross, G.J.; Tweddell, J.S.; Hogg, N. Nitrite confers protection against myocardial infarction: Role of xanthine oxidoreductase, NADPH oxidase and KATP channels. J. Mol. Cell. Cardiol. 2007, 43, 437-444.

11. Goodman, L.S.; Gillman, A.; Laurence, L.B.; Lazo, J.S. Goodman and Gillman the Pharmacological Basis of Therapeutics, 13th ed.; The McGraw-Hill Companies, Inc.: 1325 Avenue of the Americas, New York, NY 10019, USA, 2018; pp. 823-872.

12. Talukder MA, H.; Zweier, J.L.; Periasamy, M. Targeting calcium transport in ischaemic heart disease. Cardiovasc. Res. 2009, 84, 345-352.

13. Kim, Y.-J.; Ahn, J.K.; Shin, K.-A.; Kim, C.-H.; Lee, Y.-H.; Park, K.-M. Correlation of Cardiac Markers and Biomarkers With Blood Pressure of Middle-Aged Marathon Runners. J. Clin. Hypertens. 2015, 17, 868-873.

14. Akila, P.; Vennila, L. Chlorogenic Acid a dietary polyphenol attenuates isoproterenol induced myocardial oxidative stress in rat myocardium: An in Vivo Study. Biomed. Pharmacother. 2016, 84, 208-214.

15. Ighodaro, O.M.; Akinloye, O.A. First Line Defence Antioxidants-Superoxide Dismutase (SOD), Catalase (CAT) and Glutathione Peroxidase (GPX): Their Fundamental Role in the Entire Antioxidant Defence Grid. Alexandria Med. J. 2018, 4, 287-293.

16. Mythili, S.; Malathi, N. Diagnostic markers of acute myocardial infarction. Biomed. Rep. 2015, 3, 743-748.

17. Kubler, W.; Haass, M. Cardioprotection: Definition, classification, and fundamental principles. Heart 1996, 75, 330-333.

18. Egred, M.; SShaw, B.; Mohammad Waitt, P.; Rodrigues, E. Under-use of beta-blockers in patients with ischemic heart disease and concomitant chronic obstructive pulmonary disease. QJM Int. J. Med. 2005, 98, 493-497.

19. Khan, M.; Gilani, A.H. Studies on blood pressure lowering, vasodilator and cardiac suppressant activities of Vitex negundo: Involvement of $\mathrm{K}^{+}$channel activation and $\mathrm{Ca}^{++}$channel blockade. Int. J. Pharmacol. 2015, 11, 137-142.

20. Afsheen, N.; Khalil-ur-Rehman Jahan, N.; Ijaz, M.; Manzoor, A.; Khan, K.M.; Hina, S. Cardioprotective and Metabolomic Profiling of Selected Medicinal Plants against Oxidative Stress. Oxidative Med. Cell. Longev. 2018, 9819360. 
The 1st International Electronic Conference on Antioxidants in Health and Disease, 1-15 December 2020

21. Patwardhan, B.; Vaidya, A.D.B.; Chorghade, M. Ayurveda and natural products drug discovery. Curr. Sci. 2004, 86, 789-799.

22. Lahlou, M. The success of natural products in drug discovery. Pharmacol. Pharm. 2013, 4, 17-31.

23. Bhatia, K.; Rahman, S.; Ali, M.; Raisuddin, S. In vitro antioxidant activity of Juglans regia L. bark extract and its protective effect on cyclophosphamide-induced urotoxicity in mice. Redox. Rep. 2006, 11, 273-79.

24. Sun, Y.; Qi, G.; Li, D.; Meng, H.; Zhu, Z.; Zhao, Y.; Qi, Y.; Zhang, X. Walnut (Juglans regia L.) Kernel Extracts Protect Against Isoproterenol-Induced Myocardial Infarction in Rats. Rejuvenation Res. 2018, 22, 306-312.

25. Vogel, J.A.; Reischauer, C. About a new organic body in the fruit shells of Juglans regia. Arch. Pharm. 1857, $141,67$.

26. Stickney, J.; Hoy, P.Toxic action of black walnut. Trans. Wis. State Hort. Soc. 1881, 11, $166-67$.

27. Auyong, T.K.; Westfall, B.A.; Russell, R.L. Pharmacological aspects of juglone. Toxicon 1963, 1, $235-239$.

28. Ahmad, T.; Suzuki, Y.J. Juglone in Oxidative Stress and Cell Signaling. Antioxidants 2019, 8, 91.

29. Ahmad, T.; Shah, A.J.; Roberts, R. Mechanisms mediating the vasodilatory effects of juglone in porcine isolated coronary artery. Eur. J. Pharmacol. 2020a, 866, 172815.

30. Ahmad, T.; Khan, T.; Alamgeer; Shah, A.J. Juglone as antihypertensive agent acts through multiple vascular mechanisms. Clin. Exp. Hypertens. 2020b, 42, 335-344.

31. Clark, A.M.; Jurgens, T.M.; Huord, C.D. Antimicrobial activity of juglone. Phytother. Res. 1990, 4, 11-14.

32. Drage, S.; Engelmeier, D.; Bachmann, G.; Sessitsch, A.; Mitter, B.; Hadacek, F. Combining microdilution with MicroResp ${ }^{\mathrm{TM}}$ : Microbial substrate utilization, antimicrobial susceptibility and respiration. J. Microbiol. Methods 2012, 88, 399-412.

33. Bhargava, U.C.; Westfall, B.A. Antitumor activity of Juglans nigra (black walnut) extractives. J. Pharm. Sci. 1968, 57, 1674-1677.

34. Xu, H.-L.; Yu, X.-F.; Qu, S.-C.; Zhang, R.; Qu, X.-R.; Chen, Y.-P.; Ma, X.-Y.; Sui, D.-Y. Anti-proliferative effect of Juglone from Juglans mandshurica Maxim on human leukemia cell HL-60 by inducing apoptosis through the mitochondria-dependent pathway. Eur. J. Pharmacol. 2010, 645, 14-22.

35. Wang, P.; Gao, C.; Wang, W.; Yao, L.P.; Zhang, J.; Zhang, S.D.; Li, J.; Fang, S.H.; Fu, Y.J. Juglone induces apoptosis and autophagy via modulation of mitogen-activated protein kinase pathways in human hepatocellular carcinoma cells. Food Chem. Toxicol. 2018, 116, 40-50.

36. Zakavi, F.; Golpasand Hagh, L.; Daraeighadikolaei, A.; Farajzadeh Sheikh, A.; Daraeighadikolaei, A.; Leilavi Shooshtari, Z. Antibacterial Effect of Juglans Regia Bark against Oral Pathologic Bacteria. Int. J. Dent. 2013, 2013, 854765.

37. Chobot, V.; Hadacek, F. Milieu-dependent pro-and antioxidant activity of juglone may explain linear and nonlinear effects on seedling development. J. Chem. Ecol. 2009, 35, 383-390.

38. Jin, R. A DFT study on the radical scavenging activity of juglone and its derivatives. J. Mol. Struct. THEOCHEM 2010, 939, 9-13.

39. National Research Council (NRC). Guide for the Care and Use of Laboratory Animals; National Academy Press: Washington, DC, USA, 1996.

40. Wang, S.; Tian, S.; Yang, F.; Yang, H.; Yang, X.; Du, G. Cardioprotective effect of salvianolic acid A on isoproterenol-induced myocardial infarction in rats. Eur. J. Pharmacol. 2009, 615, 125-132.

41. Li, H.; Xie, Y.-H.; Yang, Q.; Wang, S.-W.; Zhang, B.-L.; Wang, J.-B.; Cao, W.; Bi, L.-L.; Sun, J.-Y.; Miao, S.; et al. Cardioprotective effect of paeonol and danshensu combination on isoproterenol-induced myocardial injury in rats. PLoS ONE 2012, 7, e48872.

42. Sahu, B.D.; Anubolu, H.; Koneru, M.; Kumar, J.M.; Kuncha, M.; Rachamalla, S.S. Cardioprotective effect of embelin on isoproterenol-induced myocardial injury in rats: Possible involvement of mitochondrial dysfunction and apoptosis. Life Sci. 2014, 107, 59-67.

43. Ahmed, S.; Gul, S.; Ze Jaafar, H.; Moga, M.; Zia-Ul-Haq, M.; Dima, L. Anti-platelet effects of nimesulide in isoproterenol-induced myocardial ischaemia and infarction in rabbits. Acta Cardiol. 2015, 70, 401-408.

44. Ho, D.; Yan, L.; Iwatsubo, K.; Vatner, D.E.; Vatner, S.F. Modulation of $\beta$-adrenergic receptor signaling in heart failure and longevity: Targeting adenylyl cyclase type 5. Heart Fail Rev. 2010, 15, 495-512.

45. de Lucia, C.; Eguchi, A.; Koch, W.J. New Insights in Cardiac $\beta$-Adrenergic Signaling During Heart Failure and Aging. Front. Pharmacol. 2018, 9, 904. 
The 1st International Electronic Conference on Antioxidants in Health and Disease, 1-15 December 2020

46. Wexler, B.C. Myocardial infarction in young vs old male rats: Pathophysiologic changes. Am. Heart J. 1978, $96,70-80$.

47. Sambhi, M.P.; White, F.N. The electrocardiogram of the normal and hypertensive rat. Circ. Res. 1960, 8, 129-134.

48. Geng, B., Chang, L., Pan, C., Qi, Y., Zhao, J., Pang, Y., Du, J., \& Tang, C. Endogenous hydrogen sulfide regulation of myocardial injury induced by isoproterenol. Biochem Biophys Res Commun. 2004. 318(3), 756763.

49. Rajadurai, M.; Prince, P.S. Preventive effect of naringin on cardiac mitochondrial enzymes during isoproterenol-induced myocardial infarction in rats: A transmission electron microscopic study. J. Biochem. Mol. Toxicol. 2007a, 21, 354-361.

50. Alpert, J.S.; Thygesen, K.; Antman, E.; Bassand, J.P. Myocardial infarction redefined-A consensus document of The Joint European Society of Cardiology/American 36(3 College of Cardiology Committee for the redefinition of myocardial infarction). J. Am. Coll. Cardiol. 2000, 36, 959-969.

51. Suchalatha, S.; Shyamala Devi, C.S. Protective effect of Terminalia chebula against experimental myocardial injury induced by isoproterenol. Indian J. Exp. Biol. 2004, 42, 174-178.

52. Thygesen, K.; Alpert Joseph, S.; Jaffe Allan, S.; Chaitman Bernard, R.; Bax Jeroen, J.; Morrow David, A.; White Harvey, D.; The Executive Group on behalf of the Joint European Society of Cardiology (ESC)/American College of Cardiology (ACC)/American Heart Association (AHA)/World Heart Federation (WHF) Task Force for the Universal Definition of Myocardial Infarction. Fourth Universal Definition of Myocardial Infarction (2018). Circulation 2018, 138, e618-e651.

53. Sabeena Farvin, K.H.; Anandan, R.; Kumar, S.H.; Shiny, K.S.; Sankar, T.V.; Thankappan, T.K. Effect of squalene on tissue defense system in isoproterenol-induced myocardial infarction in rats. Pharmacol. Res. 2004, 50, 231-236.

54. Rajadurai, M.; Prince, P.S. Preventive effect of naringin on cardiac markers, electrocardiographic patterns and lysosomal hydrolases in normal and isoproterenol-induced myocardial infarction in Wistar rats. Toxicology 2007b, 230, 178-188.

55. Panda, V. S.; Naik, S. R. Cardioprotective activity of Ginkgo biloba phytosomes in isoproterenol-induced myocardial necrosis in rats: a biochemical and histoarchitectural evaluation. Exp. Toxicol. Pathol. 2008. 60, 397-404.

56. Roy, A.J.; Prince PS, M. Protective effects of sinapic acid on cardiac hypertrophy, dyslipidemia and altered electrocardiogram in isoproterenol-induced myocardial infarcted rats. Eur. J. Pharmacol. 2013, 699, $213-$ 218.

57. Takeda, S.; Yamashita, A.; Maeda, K.; Maeda, Y. Structure of the core domain of human cardiac troponin in the Ca $\left(^{2+}\right)$-saturated form. Nature 2003, 424, 35-41.

58. Body, R.; McDowell, G.; Carley, S.; Wibberley, C.; Ferguson, J.; Mackway-Jones, K. A FABP-ulous "rule out" strategy? Heart fatty acid binding protein and troponin for rapid exclusion of acute myocardial infarction. Resuscitation 2011, 82, 1041-1046.

59. Roos, A.; Hellgren, A.; Rafatnia, F.; Hammarsten, O.; Ljung, R.; Carlsson, A.C.; Holzmann, M.J. Investigations, findings, and follow-up in patients with chest pain and elevated high-sensitivity cardiac troponin T levels but no myocardial infarction. Int. J. Cardiol. 2017, 232, 111-116.

60. Wallimann, T.; Wyss, M.; Brdiczka, D.; Nicolay, K.; Eppenberger, H.M. Intracellular compartmentation, structure and function of creatine kinase isoenzymes in tissues with high and fluctuating energy demands: The "phosphocreatine circuit" for cellular energy homeostasis. Biochem. J. 1992, 281, 21-40.

61. Barcelos, R.P.; Stefanello, S.T.; Mauriz, J.L.; Gonzalez-Gallego, J.; Soares, F.A.A. Creatine and the Liver: Metabolism and Possible Interactions. Mini Rev. Med. Chem. 2016, 16, 12-18.

62. Karras, D.J.; Kane, D.L. Serum markers in the emergency department diagnosis of acute myocardial infarction. Emerg. Med. Clin. N. Am. 2001, 19, 321-337.

63. Baird, M.F.; Graham, S.M.; Baker, J.S.; Bickerstaff, G.F. Creatine-Kinase- and exercise-related muscle damage implications for muscle performance and recovery. J. Nutr. Metab. 2012, 960363.

64. Peer, P.A.; Trivedi, P.C.; Nigade, P.B.; Ghaisas, M.M.; Deshpande, A.D. Cardioprotective effect of Azadirachta indica A. Juss. On isoprenaline induced myocardial infarction in rats. Int. J. Cardiol. 2008, 126, 123-126. 
The 1st International Electronic Conference on Antioxidants in Health and Disease, 1-15 December 2020

65. Akila, P.; Asaikumar, L.; Vennila, L. Chlorogenic acid ameliorates isoproterenol induced myocardial injury in rats by stabilizing mitochondrial and lysosomal enzymes. Biomed. Pharmacother. 2017, 85, 582591.

66. Agress, C.M.; Jacobs, H.I.; Glassner, H.F.; Lederer, M.A.; Clark, W.G.; Wroblewski, F.; Karmen, A.; Ladue, J.S. Serum transaminase levels in experimental myocardial infarction. Circulation. 1955, 11, 711-713.

67. Shen, J.; Zhang, J.; Wen, J.; Ming, Q.; Zhang, J.; Xu, Y. Correlation of serum alanine aminotransferase and aspartate aminotransferase with coronary heart disease. Int. J. Clin. Exp. Med. 2015, 8, 4399-4404.

68. Padmanabhan, M.; Prince, P.S.M. Preventive effect of S-allylcysteine on lipid peroxides and antioxidants in normal and isoproterenol-induced cardiotoxicity in rats: A histopathological study. Toxicology 2006, 224, 128-137.

69. Reese, S.; Vidyasagar, A.; Jacobson, L., Acun, Z.; Esnault, S.; Hullett, D.; Malter, J. S.; \& Djamali, A. The Pin 1 inhibitor juglone attenuates kidney fibrogenesis via Pin 1-independent mechanisms in the unilateral ureteral occlusion model. Fibrogenesis Tissue Repair. 2010, 3, 1.

70. Bendary, E.; Francis, R.R.; Ali HM, G.; Sarwat, M.I.; El Hady, S. Antioxidant and structure-activity relationships (SARs) of some phenolic and anilines compounds. Ann. Agric. Sci. 2013, 58, 173-181.

71. Rona, G. Catecholamine cardiotoxicity. J. Mol. Cell. Cardiol. 1985, 17, 291-306.

72. Rathore, N.; John, S.; Kale, M.; Bhatnagar, D. Lipid peroxidation and antioxidant enzymes in isoproterenol induced oxidative stress in rat tissues. Pharmacol. Res. 1998, 38, 297-303.

73. Ji, L.L.; Stratman, F.W.; Lardy, H.A. Antioxidant enzyme systems in rat liver and skeletal muscle. Influences of selenium deficiency, chronic training, and acute exercise. Arch. Biochem. Biophys. 1988, 263, 150-160.

74. Joukar, S.; Ebrahimi, S.; Khazaei, M.; Bashiri, A.; Shakibi, M. R.; Naderi, V.; Shahouzehi, B.; Alasvand, M. Co-administration of walnut (Juglans regia) prevents systemic hypertension induced by long-term use of dexamethasone: A promising strategy for steroid consumers. Pharm Biol. 2016, 55(1), 184-189.

75. Godfraind, T.. Antioxidant effects and the therapeutic mode of action of calcium channel blockers in hypertension and atherosclerosis. Philos Trans R Soc Lond B Biol Sci. 2005. 360(1464), 2259-2272.

76. Zhou, D.-J.; Mu, D.; Jiang, M.-D.; Zheng, S.-M.; Zhang, Y.; He, S.; Weng, M.; Zeng, W.-Z. Hepatoprotective effect of juglone on dimethylnitrosamine-induced liver fibrosis and its effect on hepatic antioxidant defence and the expression levels of $\alpha$-SMA and collagen III. Mol. Med. Rep. 2015, 12, 4095-4102.

Publisher's Note: MDPI stays neutral with regard to jurisdictional claims in published maps and institutional affiliations.

(C) 2020 by the authors; licensee MDPI, Basel, Switzerland. This article is an open access article distributed under the terms and conditions of the Creative Commons by Attribution (CC-BY) license (http://creativecommons.org/licenses/by/4.0/). 